Krol O, Sokolov V. Research of modified gear drive for multioperational machine with increased load capacity. Diagnostyka. 2020;

\title{
RESEARCH OF MODIFIED GEAR DRIVE FOR MULTIOPERATIONAL MACHINE WITH INCREASED LOAD CAPACITY
}

\author{
Oleg KROL, Volodymyr SOKOLOV \\ Volodymyr Dahl East Ukrainian National University, Department of Machinery Engineering \\ and Applied Mechanics, 59-a Central pr., Severodonetsk, 93400 \\ e-mail: krolos.snu.edu@gmail.com
}

\begin{abstract}
The presented work is devoted to the improvement of spur gears of the reduction drive for metal-cutting machines according to the criterion of load capacity. A feature of this article is the creation of such a constructive solution, which is aimed at finding a compromise between reducing contact loads in the engagement zone and increasing the complexity and labour intensity of the manufacturing gears process. A procedure for accelerated creation of 3D models of a gear drive and its components using the specialized software application "Shafts and Mechanical Transmissions-3D" in the environment of integrated CAD system KOMPAS-3D is proposed. A study of a new cylindrical gear transmission design with a longitudinal generatrix of axoids, confirmed by the corresponding patent solution is realized. A calculation form for the practical design and manufacture of a new design cylindrical gear is proposed.
\end{abstract}

Keywords: cylindrical gear transmission, machine gear drive, axoid generatrix, 3D model, load capacity

\section{INTRODUCTION}

Based on the aggregate-modular principle, multioperational machine tools (MT) of various layouts are created [1-3]. At the same time, a limited group of normalized nodes is developed and specialized multioperational machines are built from them, which most fully correspond to technological tasks. The layout of the machines is distinguished by the location of the spindle, the main motion drive in space, the relative position of the main nodes.

The main motion drive occupies a special position in the structure of MT. They should provide a high-productivity performance of various operations when changing the rotation frequency in a wide range $[4,5]$. In machine tools, a spindle with a cone of $40-5000 \ldots 7000 \mathrm{~min}^{-1}$ and the engine power of the main drive is associated with the dimensions of the table. In medium-sized machines with a table width of $500 \ldots 800 \mathrm{~mm}$ is $11 \ldots 15$ $\mathrm{kW}$. Moreover, the speed of the working feed reaches $8000 \ldots 10000 \mathrm{~mm} / \mathrm{min}$, the speed of fast movements $10 \ldots 12 \mathrm{~m} / \mathrm{min}$ [6].

One of the most common options for the main motion drive of machines is an option with an alternating current motor equipped with a frequency converter and gearbox based on 2-3 mechanical gears (various types of gears), to increase the range of rotational speeds and torque. This type of reduction drive provides high torque during roughing and retains the possibility of high-speed processing at speeds of about $10^{4} \mathrm{rpm}$. The standard configuration for most machines with a 40th cone involves the use of conventional two-stage and planetary gears.

The competitiveness of multioperational machines is primarily associated with factors: productivity, reliability and accuracy. At the same time, reliability is one of the main requirements made by consumers and often serves as the main criterion for assessing quality.

Productivity and reliability of machine drives are often limited by the smooth operation of pinion and gears. Therefore, the issues of improving the reliability, load capacity of the gears of the machine's main motion drive due to the improvement of design and technological solutions are relevant.

\section{LITERATURE REVIEW}

In [7-9], it is noted that, at the initial stages of the research, it is necessary to implement a search for the toolkit to describe the contour of the teeth lateral surface of spur and bevel gears. Such a description will be the basis for obtaining optimized contact conditions in a wide range of gear transmission. Important parameters include groove profile parameters, which are largely determined by the longitudinal generatrix shape of the pinion and wheel axoid.

It is also important to equip the production of gears with appropriate software for CAM systems. Promising in this regard is the software Gleason 5axis Gear Studio (G5S) [7] company Gleason Corporation. These specialized programs are intended for profiling the tooth lateral surface, 
evaluating the contact pattern and preparing the corresponding control programs for 5-axis $\mathrm{CNC}$ machines and machining centres. To make this technology truly practical, each operator, in just a few simple steps and minimal knowledge about the design of the gearbox, will be able to automatically generate the optimal program for machining parts and 3D models of gears, based on which a control program for processing them is developed.

According to [8], one of the main goals is to create a working 3D model for analyzing contact geometry, visual identification, and evaluating the relationships between the set of tooth geometric parameters. The toolkit of the designer's tools should include a method for creating a threedimensional model of the gear in the corresponding integrated CAD systems [8-10].

At the same time, the increase in reliability achieved by constructive methods often conflicts with technological improvements. Thus, within the confines of the JSME RC-268 committee, a new Invo-Planar [11] bevel gear was developed, the tooth flank of which is flat, whose transverse tooth profile is a straight line.

Processing the simplified contour of the tooth lateral surface by grinding in one pass allows you to reduce machine time for a standard gear contour by more than 10 times. Moreover, the lateral surface of the tooth is much smoother than the curved lateral surface of the tooth formed by many trajectories of the tool cutting blades. On the other hand, the progress of machine equipment, 5 coordinate centres makes it possible to accelerate the production of complex contours of the tooth lateral surface. So, on the 5-axis Gleason Heller machine, with the help of the CAM "Heller uP-Gear [7], gears are machined with the optimal geometry of the tooth flank and the contact pattern. As a cutting tool, insert disk knives are used for roughing, semifinishing and final gear cutting operations.

Another aspect, from the standpoint of the criterion of contact stresses, and therefore reliability, it is rational to increase the length of the teeth working contact, which gives an increase in the load capacity of the gear transmission. The problem of the operational aspect associated with a decrease in the process of working the contact length of the teeth in the longitudinal direction (especially at high cutting speeds) drew attention [12]. This phenomenon leads to a decrease in the length of the loaded tooth region and, as a result, to the risk of excessive contact stress. The author considers compensation methods for these mechanical deviations so that the load on the gear wheel surface is evenly distributed under normal operating conditions. A generatrix of the single or double helix type is proposed for describing the side surface of a wheel tooth to increase the contact length. Another constructive option for increasing energy efficiency by the example of differential mechanisms was proposed in [13].
Based on the analysis of the problem under consideration, improving the efficiency of various types of gears, we statement of the problem:

To develop a modernized gear design of the machine reduction drive which implements a compromise between increased reliability and sophisticated manufacturing technology on modern CNC machines.

To achieve this goal, the following tasks are proposed:

1. To develop 3D models of the main motion drive for multi-operational machines in the KOMPAS3D CAD environment using the specialized application program "Shafts and Mechanical Transmissions-3D".

2. Explore and create a new design of the gear transmission with a modified shape of the longitudinal axoids generatrix of the pinion and wheel.

\section{METHOD OF 3D MODELING MULTIOPERATIONAL TOOLS GEARBOXES DRIVE}

As the object of research, a multi-operational milling-drilling-boring machine with a six-spindle turret was selected. Increasing the level of complexity of projects in machine tool manufacture, the creation of competitive designs involves the widespread use of various computeraided design systems. In the technology of the design process, the procedures for constructing 3D models and parametric representations of parts and assembly units are important.

The research of the main structural characteristics of the machine drive is provided by the corresponding 3D modeling toolkit in integrated CAD/CAM/CAE KOMPAS-3D [14-18], in which a three-dimensional model of the machine reduction drive has been developed (Fig. 1).

In the process of creating this model, the latest functionalities of CAD KOMPAS and specialized applications were used. When developing such complex parts as the bed housing with a gear drive (speed gearbox) and the housing of a six-spindle turret, specialized CAD application libraries were used. It is significantly improved the process of geometric modeling. Using the Artisan Rendering photorealistic image module integrated into KOMPAS forms the corresponding design and understanding of the machine design [19].

The machine under consideration belongs to the class of specialized machines of the 2nd standard size, which are used in small-scale and series production and are intended for multi-operation machining of complex profile products from steel, cast iron, light and non-ferrous metals. The machine is equipped with an automatic tool changer, which is carried out by turning the sixspindle turret to the desired position according to the program. In the upper part of the bed housing, 


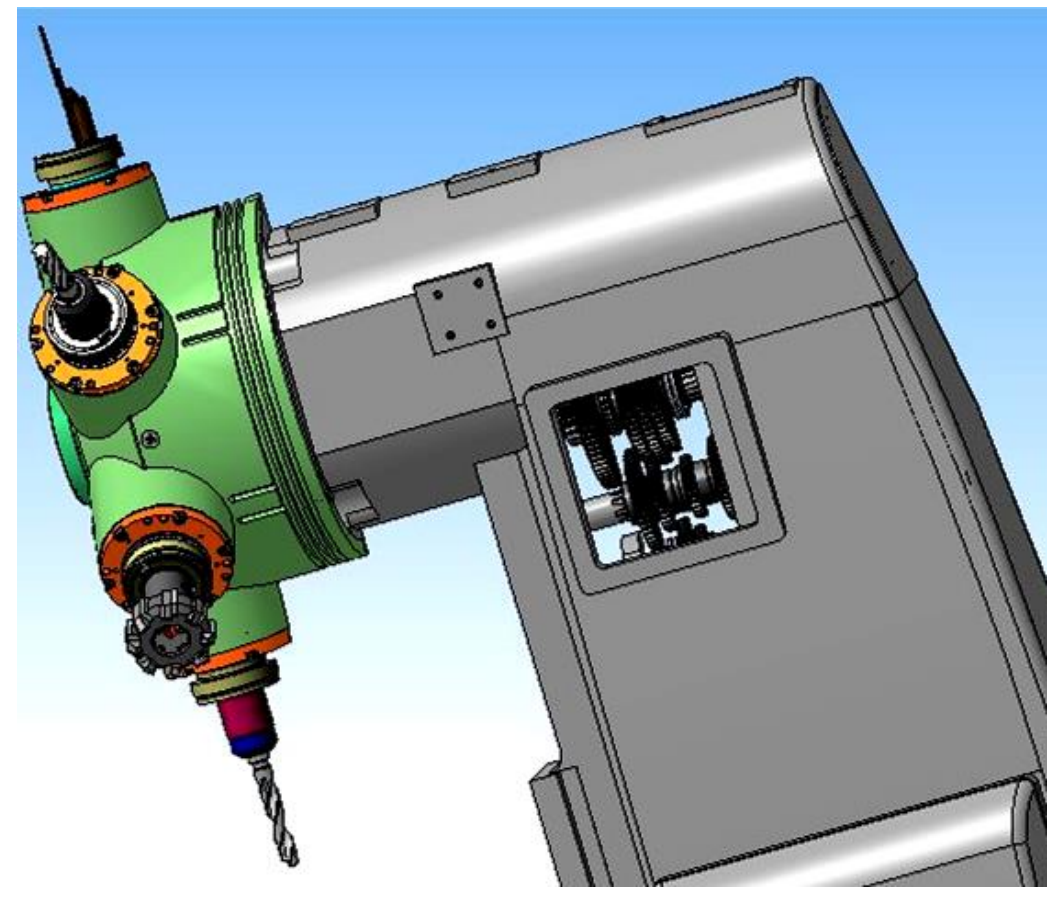

Fig. 1. 3D model main motion gear drive
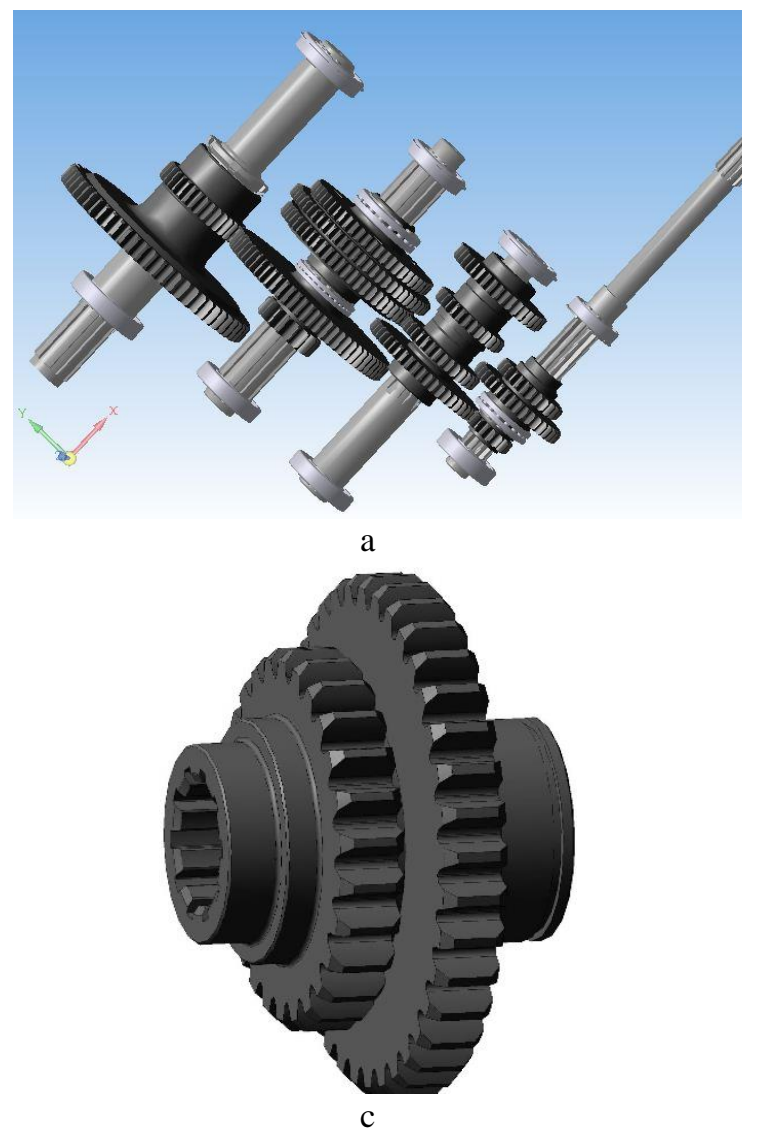
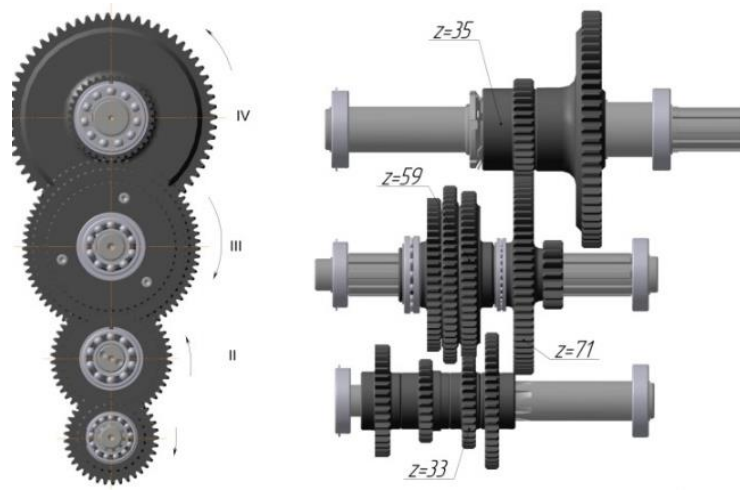

b

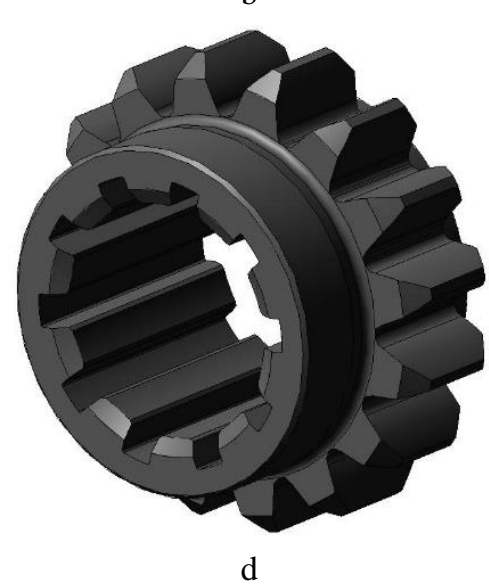

Fig. 2. 3D modeling of gear drives components: $a$ - kinematic diagram; $b$ - transverse and longitudinal layout; c - gear block $\mathrm{d}$ - drive pinion

a gearbox is mounted with a gearshift mechanism and a turret rotation mechanism (Fig. 2).

The competitiveness of multioperational machines is primarily associated with factors: productivity, reliability and accuracy. At the same time, reliability is one of the main requirements made by consumers and often serves as the main criterion for assessing quality. 


\section{RESULTS AND DISCUSSION}

Productivity and reliability of machine drives are often limited by the smooth operation of pinion and gear. Therefore, the issues of improving the reliability, the load capacity of the gear wheels of the main motion drive due to the improvement of design and technological solutions are relevant [20, 21].

First of all, it should be noted that in the known gear transmission on parallel axes, a pinion and a wheel are used, the axoids of which are cylinders with a rectilinear generatrix [11]. The disadvantage of such a gear transmission on parallel axes is the insufficient bending load capacity of the teeth because the longitudinal direction of the teeth coincides with the rectilinear axoid generatrix the gears and wheels, and the length of the teeth is limited by the width of the gearing.

The main idea of improvement is changing the shape of the longitudinal pinion and wheel axoid generatrixes [21]. The result of this modernization is an increase, ceteris paribus, the length of the teeth, which ultimately will increase the load capacity of the gear teeth in bending. The problem is achieved by receiving in a gear transmission on parallel axes, the pinion and wheel longitudinal axoid generatrix in the shape of a circular arc with radius $r_{0}$ :

$$
r_{0}=0.25 \cdot m \cdot k \cdot \psi_{b a} \cdot z_{1} \cdot(i+1)
$$

where $m$ - gearing module, $\mathrm{mm} ; k$ - coefficient that ensures the fulfillment of the obvious condition: $r_{0}>0.5 \cdot b_{W}$ what should be accepted $k>1$; $\psi_{b a}=b_{W} / a_{W}-$ gear width ratio expressed in terms of gear width $b_{W}$ and center distance $a_{W} ; z_{1}$ - the number of gear teeth; $i$ - gear ratio.

In this case, the pinion axoid in the longitudinal direction is concave, and the axoid of the wheel in the same direction is convex.

The gear transmission on parallel axes (Fig. 3) contains a pinion 1 and a wheel 2, the longitudinal axoid generatrixes of which is a circular arc with radius $r_{0}$, operates as follows. The teeth of the gear 1 in an amount $z_{1}$ that rotates at an angular speed $\omega_{1}$ are engaged with the teeth of the wheel 2 in an amount $z_{2}$. In this case, the angular speed $\omega_{1}$ of the pinion 1 is converted into the angular speed $\omega_{2}$ of the wheel 2. As a result, the gear ratio of the gearing $i=\omega_{1} / \omega_{2}$ is needed.

The surfaces of the gear teeth are the envelope surfaces of a disk milling cutter with straight cutting edges in relative motion and are described by the following system of equations (1):

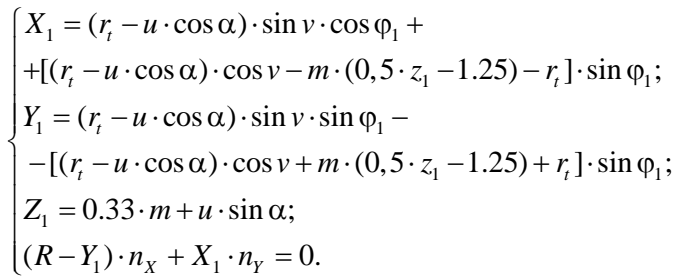

Here: $\quad r_{t}=m \cdot\left[0,25 \cdot k \cdot \psi_{b a} \cdot z_{1} \cdot(i+1)+1,25\right]$

nominal radius of a disk milling cutter; $\alpha=20^{\circ}-$ the angle of inclination of the straight cutting edges of the disk milling cutter;

$u, v$ - independent variable parameters of pinion teeth; $\varphi_{1}=0.5 \cdot \omega_{1} \cdot m \cdot z_{1}-$ the angle of pinion rotation relative to the axis $Z_{1} ;\left(\omega_{1}\right.$ - pinion angular speed);

$n_{X}=-\left(r_{t}-u \cdot \cos \alpha\right) \cdot\left(\cos v \cdot \sin \varphi_{1}+\sin v \cdot \cos \varphi_{1}\right) \cdot \sin \alpha$ - the projection of the normal to the surface of the pinion tooth on the axis $X$;

$n_{Y}=\left(r_{t}-u \cdot \cos \alpha\right) \cdot\left(\cos v \cdot \cos \varphi_{1}-\sin v \cdot \sin \varphi_{1}\right) \cdot \sin \alpha$

- the projection of the normal to the surface of the pinion tooth on the axis $Y$;

$R=m \cdot\left(0,5 \cdot z_{1}-1.25\right)+r_{t}$.

The teeth surface of the wheel is an envelope of surfaces relative to the surfaces of the pinion teeth (1) with the same radius of the axoid $r_{0}$, but convex in the longitudinal direction.

In Fig. 3 shows a general view of the gear transmission on parallel axes, contains a pinion 1 and a wheel 2. The 3D-model of a modernized cylindrical gear transmission (Fig. 3) in the "Shafts and mechanical gears-3D" module of CAD KOMPAS-3D was developed

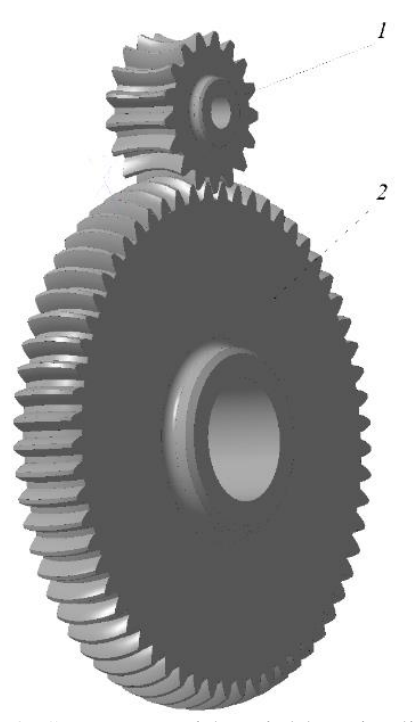

Fig. 3. Spur gear with axial longitudinal generatrix in the form of a circular arc

In Fig. 4 and Fig. 5 show fragments of cutting the pinion teeth 1 by a disk cutter 3 during a running-in process, in which the rotation of the pinion 1 with an angular speed $\omega_{1}$ is consistent with the translational movement of the disk milling cutter 
3 at a speed $V_{3}=\omega_{1} \cdot r_{1}=0.5 \cdot \omega_{1} \cdot m \cdot z_{1}$, where $r_{1}$ pitch radius of the pinion in the average frontal cross-section. On the example of pinion 1, it is shown how, due to the curved shape of the axoid, the length of the tooth increases - from the size $b_{W}$ in the known gear transmission to the length of the arc $\cup M N$ in the modernized gear transmission. If the parameter $r_{t}$ is expressed through, $r_{0}$ (Fig. 5):

$r_{t}=r_{0}+1.25 \cdot m=m \cdot\left[0.25 \cdot k \cdot \psi_{b a} \cdot z_{1} \cdot(i+1)+1.25\right]$, that ratio of variables $\cup M N$ to $b_{W}$ determine by the dependence:

$$
\begin{aligned}
& \frac{\cup M N}{b_{W}}=\left[k+\frac{5}{\psi_{b a} \cdot z_{1} \cdot(i+1)}\right] \times \\
& \times \arcsin \left[\frac{0.25 \cdot \psi_{b a} \cdot z_{1} \cdot(i+1)}{0.25 \cdot k \cdot \psi_{b a} \cdot z_{1} \cdot(i+1)+1.25}\right] .
\end{aligned}
$$
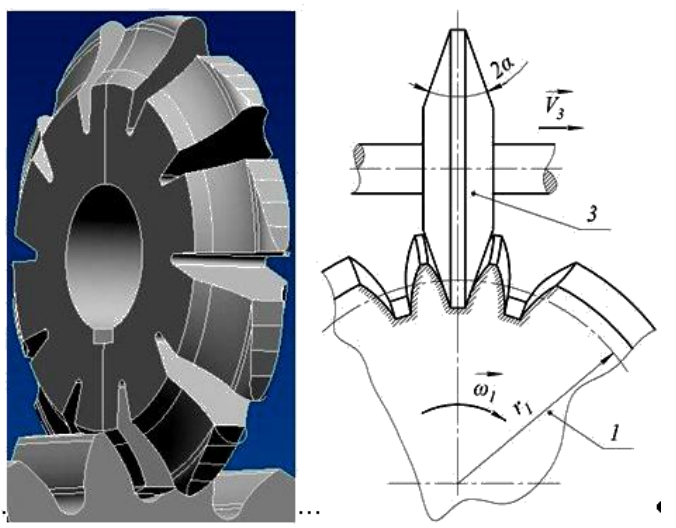

Fig. 4. Cutting gear teeth with a modular disk milling cutter when coordinating movements

Calculations show that in a gear transmission on parallel axes with constant parameters, when the coefficient varies within the boundary $k=1.2 \ldots 1.5$, the ratio $\cup M N / b_{W}$ changes from 1.13 to 1.08 . This means that the bending stress in the teeth of the modernized gear transmission will be $8 \ldots 13 \%$ less than in the known gear transmission.

Along with the design component, the contact component is also influenced by the technological component associated with the quality of the formation of the pinion tooth back surface. When machining the relieving tooth back surface by grinding it is rather difficult to choose the cutting conditions. In this regard, the ideas of choosing and optimizing the grinding process presented in $[22,23]$ are of interest.

The operation of the proposed gearbox option is associated with wear processes and the likelihood of breakdowns [24]. To analyze these operational phenomena and prevent possible breakdowns, it is rational to use the thermovision method with the Termovision Processing Software, developed by the Machinery Systems Division, Wroclaw University of Technology and tested on the example of a two- stage belt conveyor gearbox [25]. Another method is the Stochastic Resonance method [26-28], which is based on the calculation of residual signals during the operation of a cylindrical gearbox, and under conditions of normative functioning is used.

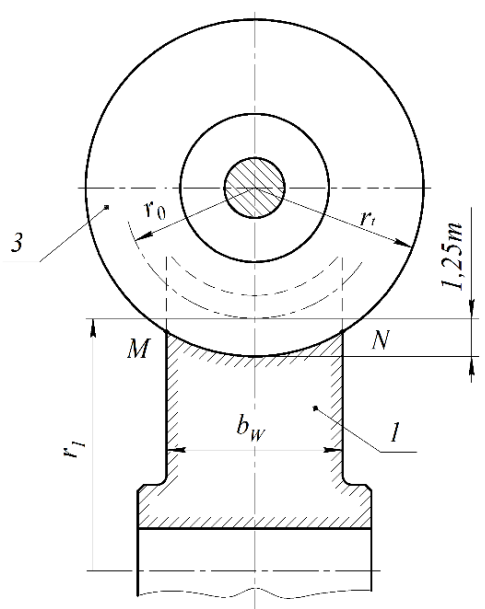

Fig. 5. Pinion with extended tooth length

In case of continuous operation, it is necessary to monitor the vibrations of the gear drive. In this regard, a promising method is the control of distributed wear (pitting corrosion) in planetary gears, proposed in [29].

\section{CONCLUSIONS}

This research describes the new design of a cylindrical gear transmission of a stepped reduction drive for the machine tools. At the initial stages of development, a three-dimensional model of the reduction drive and its component in the integrated CAD system KOMPAS-3D was formed. The article suggests moving away from the standard cylindrical spur engagement profile to the design version of the longitudinal axoid generatrix in the form of a circular arc with radius $r_{0}$ satisfying the condition $r_{0}>0.5 \cdot b_{W}$. This allows you to implement a compromise solution: with an extended tooth width of the wheel and, as a result, increased load capacity on the one hand (about 8-13\%) and rather complicated manufacturing technology. The latter is achieved using disc milling cutters with straight cutting edges.

\section{REFERENCES}

1. Yakovenko I, Permyakov A, Naboka O, Prihodko O, Havryliuk Y. Parametric Optimization of Technological Layout of Modular Machine Tools. In: Ivanov V. et al eds. Advances in Design, Simulation and Manufacturing III. DSMIE 2020. Lecture Notes in Mechanical Engineering. Springer, Cham. 2020. https://doi.org/10.1007/978-3-03050794-7_9

2. Kushnir E, Portman V, Aguilar A. et al. Layout evaluation at earlier stages of machine tool design: form-shaping function-based approach. Int $\mathrm{J} \mathrm{Adv}$ 
Manuf Technol. 2017; 90: 3333-3346 https://doi.org/10.1007/s00170-016-9667-0

3. Krol O, Sokolov V. Parametric Modeling of transverse layout for machine tool gearboxes. In: Gapiński B, Szostak M, Ivanov V. (eds) Advances in Manufacturing II. Lecture Notes in Mechanical Engineering. Springer, Cham 2019; 4: 122-130. https://doi.org/10.1007/978-3-030-16943-5_11

4. Saravanakumar R, Nishanth M, Govindarajan C, Vattikuti C. Fabrication and usage of multipurpose mechanical machine using scotch yoke mechanism September. IOP Conference Series. Materials Science and Engineering. 2018; 402(1): 012188. https://doi.org/10.1088/1757-899X/402/1/012188

5. Srivastava Sharad, Srivastava Shivam, Khatri C.B. Multi-Function Operating Machine: A Conceptual Model. IOSR Journal of Mechanical and Civil Engineering 2014; 14 (1): 69-75.

6. Avramova TM, Bushuev VV, Gilova, L.Ya. Handbook on metal-cutting machine tools. Moscow: Mechanical Engineering. 2012. Russian.

7. Gaiser U. 5-axis gear manufacturing gtts practical. Geartechnology 2017; March/April: 32-34.

8. Bjionowski B. A practical approach for modelling a bevel gear Geartechnology 2015; March/April: 68-75.

9. Krol O, Sokolov V. Parametric Modeling of Gear Cutting Tools. In: Gapiński B., Szostak M., Ivanov V. (eds) Advances in Manufacturing II. Lecture Notes in Mechanical Engineering. Springer, Cham 2019; 4: 311. https://doi.org/10.1007/978-3-030-16943-5_1

10. Pavlenko I, Liaposhchenko O, Ochowiak M, Olszewski R, Demianenko M, Starynskyi O, Ivanov V, Yanovych V, Włodarczak S, Doligalski M. ThreeDimensional Mathematical Model of the Liquid Film Downflow on a Vertical Surface. Energies 2020; 13(8): 1938. https://doi.org/10.3390/en13081938

11. Kubo A, Ueda A. Gear geometry as a function of the production method. The Proceedings of the JSME international conference on motion and power transmission; 2017; 51: 27-44

https://doi.org/10.1299/jsmeimpt.2017.02-06

12. Amendola JB, Amendola JB. III, Yatzook D. Longitudinal tooth contact pattern shift. Geartechnology. 2012; May: 63-67.

13. Malashchenko V, Strilets O, Strilets V, Kłysz S. Investigation of the energy effectiveness of multistage differential gears when the speed is changed by the carrier. Diagnostyka. 2019; 20(4): 5764. https://doi.org/10.29354/diag/112397

14. Brecher C, Fey M., Daniels M. Modeling of PositionTool- and Workpiece-Dependent Milling Machine Dynamics. High Speed Mach. 2016; 2: 15-25. https://doi.org/10.1515/hsm-2016-0002

15. Kong J, Cheng X. Modal analysis of CNC lathe's spindle based on finite element. Advances in Engineering Research (AER). 2017; 148: 318-321. https://doi.org/10.2991/wartia-17.2017.60

16. Krol O, Porkuian O, Sokolov V, Tsankov P. Vibration stability of spindle nodes in the zone of tool equipment optimal parameters. Comptes rendus de l'Acade'mie bulgare des Sciences. 2019; 72(11): 1546-1556. https://doi.org/10.7546/CRABS.2019.11.12

17. Pavlenko I, Simonovskiy V, Demianenko M. Dynamic analysis of centrifugal machines rotors supported on ball bearings by combined application of 3D and beam finite element models. IOP Conf. Ser.: Mater. Sci. Eng. 2017; 233: 012053. https://doi.org/10.1088/175799X/233/1/012053
18. Petrakova E, Sumatokhin V. Development algorithm for creating parametric 3D models, controlled by MathCad calculations, to study parameters of enclosed gear housing. In: Radionov A, Kravchenko O, Guzeev V, Rozhdestvenskiy Y. (eds) Proceedings of the 5th International Conference on Industrial Engineering. ICIE 2019. Lecture Notes in Mechanical Engineering. Springer, Cham. 2020; 473-483.

https://doi.org/10.1007/978-3-030-22041-9_51

19. Malukh V. We test Artisan Rendering for KOMPAS3D. Isicad. 2018; 170: 10.

20. Syzrantsev V, Pazyak A. Contact strength calculation of straight bevel precessional gear with small shaft angle. In: Radionov A, Kravchenko O, Guzeev V, Rozhdestvenskiy Y. (eds) Proceedings of the 5th International Conference on Industrial Engineering. ICIE 2019. Lecture Notes in Mechanical Engineering. Springer, Cham. 2020; 197-204. https://doi.org/10.1007/978-3-03022041-9_23

21. Shevchenko SV, Mukhovaty OA, Krol OS. Nonclereance worm gear. Patent of Ukraine 2015; 95715.

22. Kotliar A, Gasanov M, Basova Y, Panamariova O, Gubskyi S. Ensuring the reliability and performance criterias of crankshafts. Diagnostyka. 2019; 20(1): 23-32. https://doi.org/10.29354/diag/99605

23. Syzyi Y, Ushakov O, Slipchenko S, Basova Y, Ivanova M. Simulation of the contact temperature in the cylindrical plunge grinding process. Diagnostyka. 2020;21(2):77-86. https://doi.org/10.29354/diag/122532

24. Antsupov AV, Slobodianskii MG, Antsupov VA. Analytical model of wear-out failures in spur gears of external gearing. In: Radionov A, Kravchenko O, Guzeev V, Rozhdestvenskiy Y. (eds) Proceedings of the 5th International Conference on Industrial Engineering. ICIE 2019. Lecture Notes in Mechanical Engineering. Springer, Cham. 2020; 75-81.https://doi.org/10.1007/978-3-030-22041-9_9

25. Błażej R, Sawicki M, Konieczna M, Kozłowski T, Kirjanów A. Automatic analysis of themrograms as a means for estimating technical of a gear system, Diagnostyka. 2016; 17(2): 43-48.

26. Mba CU, Marchesiello S, Fasana A, Garibaldi L. On the use of stochastic resonance for fault detection in spur gearboxes. Diagnostyka. 2017;18(3):3-13

27. Sokolov V, Krol O, Stepanova O. Choice of correcting link for electrohydraulic servo drive of technological equipment. In: Ivanov V. et al. (eds) Advances in Design, Simulation and Manufacturing II. DSMIE 2019, LNME, Springer, Cham. 2020; 4: 702-710. https://doi.org/10.1007/978-3-030-22365$\underline{6.70}$

28. Sokolov V, Krol O, Stepanova O. Nonlinear simulation of electrohydraulic technological equipment. J. Physics: Conf. Series. VSPID20182019; 1278: 012003. https://doi.org/10.1088/1742-6596/1278/1/012003

29. Berlato F, D'elia G, Battarra M, Dalpiaz G. Condition monitoring indicators for pitting detection in planetary gear units. Diagnostyka. 2020; 21(1): 310. https://doi.org/10.29354/diag/116079

Received 2020-05-12

Accepted 2020-08-03

Available online 2020-08-04 


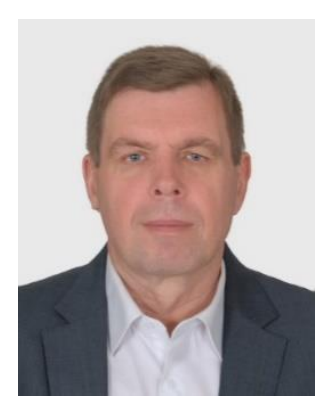

Volodymyr SOKOLOV

(ORCID 0000-0003-0459-

1824), Doctor of Sciences,

Head of the Machinery

engineering and applied mechanics department of the Volodymyr Dahl East

Ukrainian National

University, Severodonetsk,

Ukraine.

Main directions of scientific research: automatic drives of technological equipment, dynamics and regulation of technological systems.

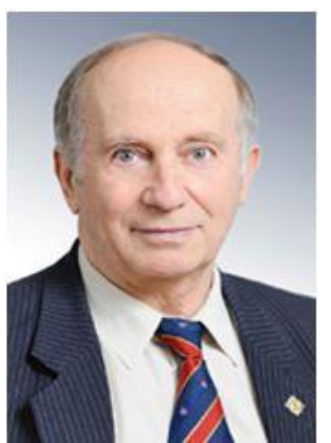

Oleg KROL (ORCID 00000003-0193-2750),

$\mathrm{PhD}$,

Professor of the Machinery engineering and applied mechanics department of the Volodymyr Dahl East Ukrainian National University, Severodonetsk, Ukraine.

Main directions of scientific research: 3D- and parametrical modelling, machine tool design, $\mathrm{CAD} / \mathrm{CAM} / \mathrm{CAE}$ system, optimization in mechanical engineering, mechanical transmission reliability 